\title{
Nureksain Tes Ulangan Umum Nganutin Taksonomi Bloom lan Peplajahan Basa Bali Kelas VII ring SMP Negeri 5 Singaraja Semester Ganjil Warsa 2016/2017
}

\author{
I Md. Cahyadi ${ }^{1}$, I. B. Md. Ludy Paryatna ${ }^{1}$, I. B. Rai ${ }^{2}$ \\ Jurusan Pendidikan Bahasa Bali \\ Universitas Pendidikan Ganesha \\ Singaraja, Indonesia \\ e-mail: \{imadecahyadi@rocketmail.com, idabagusludy@gmail.com, \\ ibrai cangapit@yahoo.com\}@undiksha.ac.id
}

\begin{abstract}
KUUB
Tetilikan puniki nlatarang indik (1) Kaanutan pitaken tes ring RPP peplajahan basa Bali, (2) Kaanutan pitaken tes peplajahan basa Bali anut ring taksonomi bloom. Palihan tetilikan puniki inggih punika deskriptif kualitatif. Jejering tetilikan puniki inggih punika tes ulangan umum. Panandang tetilikan puniki (1) kaanutan pitaken tes ring RPP, (2) pitaken tes sane anut ring taksonomi bloom. Kramaning tetilikan (1) dokumentasi. Piranti tetilikan (1) dokumentasi marupa tes, $R P P, L K S$. Data tureksa (1) nyelehin data, (2) nyajiang data, (3) pamicutet. Manut data tureksa, saking seket pitaken tes wenten telung dasa nem pitaken tes sane anut ring RPP. Wenten patbelas pitaken tes sane nenten anut ring RPP. Pitaken tes ulangan umum ring ranah kognitif kawangun antuk $\mathrm{C} 1$ ingatan, $\mathrm{C} 2$ pangresep, C4 nureksain. Ring ranah afektif kawangun antuk A4 parikrama, A5 karakteristik. Ring ranah psikomotor wantah kawangun antuk P3 reaksi sane kaarahang.
\end{abstract}

Kruna jejaton: tes ulangan umum, taksonomi bloom

\begin{abstract}
ABSTRAK
Penelitian ini menjelaskan (1) Kecocokan pertanyaan tes dengan RPP pelajaran bahasa Bali, (2) Pertanyaan tes pelajaran bahasa Bali cocok dengan taksonomi bloom. Rancangan penelitian yang digunakan adalah deskriptif kualitatif. Subjek penelitian adalah tes ulangan umum. Objek penelitian (1) kecocokan pertanyaan tes dengan RPP pelajaran, (2) pertanyaan tes yang cocok dengan taksonomi bloom. Metode penelitian (1) dokumentasi. Instrumen penelitian (1) dokumentasi berupa tes, RPP, LKS. Analisis data (1) reduksi data, (2) penyajian data, (3) penyimpulan. Dari analisis data, lima puluh pertanyaan tes ada tiga puluh enam pelajaran tes cocok dengan RPP pelajaran. Ada empat belas pelajaran tes tidak cocok dengan RPP pelajaran. Pertanyaan tes ulangan umum di ranah kognitif di bangun oleh $\mathrm{C} 1$ ingatan, $\mathrm{C} 2$ pemahaman, $\mathrm{C} 4$ analisis. Di ranah afektif di bangun oleh A4 organisasi, A5 karakteristik. Di ranah psikomotor hanya di bangun oleh P3 reaksi yang di arahkan.
\end{abstract}

Kata kunci: tes ulangan umum, taksonomi bloom 


\begin{abstract}
This study explains (1) Compatibility of test questions with RPP of Balinese lessons, (2) Questions of the Balinese lesson test match taxonomy of bloom. Research design used is descriptive qualitative. Subject the study was a generalized test. Object the study (1) suitability of test questions with lesson lesson, (2) test questions that match the taxonomy of bloom. Methods of research (1) documentation. Research instrument (1) documentation in the form of test, RPP, LKS. Analysis data (1) data reduction, (2) data presentation, (3) inference. From analysis data, fifty test questions there are thirty six lesson test matched with lesson plans. There are fourteen lesson test do not match the lesson. General repetition test questions in cognitive domain are built by $\mathrm{C} 1$ memory, C2 comprehension, C4 analysis. The affective domain in the wake of the A4 organization, A5 characteristics. The psychomotor realm only in the wake of P3 reaction in the direction
\end{abstract}

Keywords: general test, taxonomy bloom

\section{PURWAKA}

Peplajahan basa Bali kadadosang peplajahan sane utama ri sajeroning paajah-ajah mawit saking undagan sekolah dasar kantos sekolah menengah atas ring sajebag jagat Bali. Peplajahan basa Bali sane kaicen ring undagan SD, SMP, SMA punika taler anggen utsaha ngajegang basa Bali lan budaya Bali pamekasnyane. Ngenenin indik awig-awig pemrentah, peplajahan basa Bali patut kalaksanayang utawi kaicenin galah 2 jam awuku mawit saking SD kantos SMA utawi SMK ring Bali.

Ring sekolah pamekasnyane
sane dados genah para sisia ngamolihang paajah-ajah mangda sekolah punika prasida ngutamaang peplajahan basa Bali sane dados cihna kahuripan ring jagat Bali. Majeng para guru basa Bali utamannyane ring sekolah mangda prasida ngenter peplajahan basa Bali punika mangda para sisia tatas uning lan karesep ngenenin indik paajah-ajah sane sampun kawedarang utawi kaicenin olih guru ring kelas. Sisia taler sane dados penandang para guru ri tatkala ngicen paajah-ajah ring kelas mangda ngulengang kayun ri tatkala guru ngicenin ajah-ajahan basa Bali pamekasnyane.
Yening para sisia sampun teleb, urati, lan ngulengang kayun malajahin peplajahan basa Bali ring sekolah, pastika ri kala guru ngicenin tugas utawi ulangan para sisia prasida ngamolihang biji sane becik sane sampun anut ring KKM sane manut ring sekolah soang-soang. Ngenenin indik biji peplajahan basa Bali ring sekolah, sakadi sinalih tunggil guru basa Bali sane mapesengan Gusti Ayu Srikamaryati, S.Pd. B ring SMP Negeri 5 Singaraja, maosang "Ngenenin indik biji rata-rata tugas lan ulangan harian sisia, wenten makudang-kudang sisia sane bijinyane durung ngamolihang biji sane sedeng.

Dadosnyane sisia sane durung ngamolihang biji sane sedeng ri sajeroning tugas lan ulangan harian, sisia punika patut nyarengin malih ulangan harian (remidial). Mangda sisia punika prasida ngamolihang biji sane sedeng ri sajeroning tugas lan ulangan harian.

Kenten taler biji ulangan umum sisia, wenten makudang-kudang sisia sane biji ulangannyane durung ngamolihang biji sane sedeng. Nanging majalaran antuk ngwentenang parikrama remidial, dadosnyane sisia punika sampun prasida ngamolihang biji sane sedeng. Ngenenin indik biji ulangan umum sisia semester ganjil 
2016/2017 sampun ngranjing ring soroh sedeng, mawinan asapunika nenten makasami sisia punika prasida ngamolihang biji ulangan umum sane becik. Nanging majalaran antuk ngwentenang parikrama remidial, para sisia prasida ngamolihang biji tuntas (KKM)".

Sinalih tunggil sisia kelas VII sane mawasta Komang Linda Mahardika ring sekolah SMP Negeri 5 Singaraja maosang "Ngenenin indik tes ulangan umum semester ganjil warsa 2016/2017 peplajahan basa Bali kelas VII ring SMP Negeri 5 Singaraja, tes ulangan umum basa Bali sane akehnyane punika seket (50) pitaken sampun ngranjing ring undagan sedeng, duaning ring tes ulangan umum basa Bali punika kantun wenten pitaken-pitaken sane meweh.

Peplajahan sane kaicen olih guru ring kelas dahat mapaiketan sareng tes ulangan umum punika, krana peplajahan punika piranti sane kaanggen ngaryanin tes ulangan umum. Mangkin guru taler sarengsareng mautsaha ngicenin para sisia sane pinih becik. Sinalih tunggil utsaha sane mawiguna pisan majeng ring para sisia inggih punika guru mangda ngicenin para sisia latihan-latihan pitaken basa Bali mawit saking pitaken sane dangan kantos pitaken sane meweh. Tetujon ngicenin latihanlatihan pitaken majeng ring para sisia inggih punika ngaryanin para sisia mangda ri kala nyawis pitaken-pitaken tes ulangan umum basa Bali prasida becik.

Iriki sampun kawigunan evaluasi saking guru sane kaicen majeng ring para sisia. Manut ring wewidangan paajah-ajah, piranti evaluasi sane kaanggen sapatutnyane nganutin tata titi sane wenten ring kurikulum sane kamargiang. Kurikulum sane kaanggen ring wewidangan paajah-ajah mangkin inggih punika kurikulum 2013. Kemaon sane tilikin titiang inggih punika nganutin Kurikulum Tingkat Satuan Pendidikan (KTSP).

Evaluasi pinaka sinalih tunggil piranti sane kaanggen nureksain lan prasida kaanggen nyingak kawagedan sisia. Taler evaluasi punika prasida nyingak paobahan ring sadina-dina sisia punika. Ri kala ngamargiang evaluasi, akeh wenten piranti evaluasi sane kaanggen sakadi, tes, kuisioner, observasi miwah sane tiosan. Wenten kalih piranti evaluasi sane sering kaanggen inggih punika piranti tes lan non tes. Piranti evaluasi sane nglimbak kaanggen ri sajeroning evaluasi paajah-ajah inggih punika tes. Piranti evaluasi sane kabaos tes puniki pinaka piranti sane wangunnyane marupa pitaken lan latihan.

Tes prasida kabinayang dados tigang wangun inggih punika tes uraian, tes obyektif, tes uraian obyektif. Sinalih tunggil wangun tes inggih punika tes pilihan ganda. Nanging mangkin akeh kacingak tes obyektif punika nenten anut sareng peplajahan. Makehan mangkin guru ngicen sisiane peplajahan nenten anut sareng ajahajahan ring RPP utawi buku pedoman. Guru sapatutnyane ngicen sisiane ajah-ajahan sane anut ring peplajahan, RPP lan buku pedoman. Mangda sisia prasida nyawis tes punika ri kala gurune ngicenin tes.

Duaning ring aab mangkin akeh para guru kacingak ri kala ngaryanin pitaken-pitaken tes ulangan punika nenten anut ring tata titi ngaryanin tes taler nenten nguratiang peplajahan sane sampun kawedarang.

Tetilikan puniki kamargiang anggen nguningin napike pitakenpitaken tes ulangan umum semester ganjil warsa 2016/2017 peplajahan basa Bali kelas VII ring SMP Negeri 5 Singaraja sampun anut utawi nenten sareng RPP peplajahan utawi buku pedoman. Duaning ring panglimbak 
aab mangkin akeh pitaken-pitaken tes ulangan umum punika nenten anut sareng peplajahan sakadi RPP lan buku pedoman sane kaicen olih guru majeng ring para sisia ring kelas. Taler tetilikan puniki kamargiang mangda prasida anggen tetimbangan olih para guru ring sekolah ri tatkala ngaryanin tes sane kaicen majeng ring para sisia.

Sakadi sane sampun katlatarang ring ajeng, panilik madue pangrasa jagi nglaksanayang tetilikan indik Nureksain Tes Ulangan Umum Nganutin Taksonomi bloom Lan Peplajahan Basa Bali Kelas VII Ring SMP Negeri 5 Singaraja Semester Ganjil Warsa 2016/2017.

Bantang pikobet tetilikan: (1) Napike anut pitaken-pitaken tes ulangan umum semester ganjil warsa 2016/2017 ring RPP peplajahan basa Bali kelas VII ring SMP Negeri 5 Singaraja? (2) Napi wenten makudangkudang pitaken tes ulangan umum semester ganjil warsa 2016/2017 peplajahan basa Bali kelas VII ring SMP Negeri 5 Singaraja anut ring taksonomi bloom?

Tetujon tetilikan: (1) Mangda uning sane nganutin pitaken-pitaken tes ulangan umum semester ganjil warsa 2016/2017 ring RPP peplajahan basa Bali kelas VII ring SMP Negeri 5 Singaraja, (2) Mangda uning makudang-kudang pitaken tes ulangan umum semester ganjil warsa 2016/2017 peplajahan basa Bali kelas VII ring SMP Negeri 5 Singaraja anut ring taksonomi bloom.

Kawigunan pamucuk saking pikolih tetilikan puniki inggih punika prasida ngicen kaweruhan indik tes ulangan umum lan pikolih tetilikan puniki mangda prasida ngicen kawigunan majeng ring panglimbak paajah-ajah pamekasnyane ring peplajahan basa Bali. Kawigunan panglimbak sane kapolihang: (1) majeng ring guru basa Bali, tetilikan puniki kaaptiang mangda prasida mawiguna dados cihna indik kawagedan ri kala ngaryanin piranti evaluasi sane marupa tes pilihan ganda, (2) majeng ring panilik, tetilikan puniki kaaptiang mangda prasida ngicen pengalaman majeng ring panilik sakadi calon guru mangda uning sorohsoroh tes, pangaryanan tes, lan sane lianan. Lianan saking tetilikan puniki mangda prasida ngicen kaweruhan majeng ring panilik ri kala nyurat karya ilmiah, (3) majeng ring panilik sane lianan, tetilikan puniki kaaptiang prasida kaanggen tetimbang ri kala nglaksanayang tetilikan sane pateh, lan prasida kaanggen pamargi ri kala nglaksanayang tetilikan salanturnyane, (4) majeng ring wewidangan paajahajah, tetilikan puniki kaaptiang mangda prasida dados tetuladan ri kala nglaksanayang paajah-ajah, utamannyane peplajahan basa Bali, Ian makarya pitaken utawi soal sane patut.

Sepat siku-siku dahat mabuat pisan duaning prasida ngicenin pamargi lan ngwantu panilik muputang tetilikannyane. Sepat siku-siku sane kanggen, sakadi: (1) teges evaluasi pikenoh malajah; (2) tetujon evaluasi; (3) teknik evaluasi; (4) wangun tes; (5) nureksain tes pilihan ganda sareng taksonomi bloom; (6) paiketan peplajahan sareng tes pilihan ganda.

Teges evaluasi pikenoh malajah, Daryanto (2005:1) maosang evaluasi inggih punika tata cara mupulang kawiaktian sane sistematis mangda prasida minayang kawiaktian ring soang-soang sisia lan mangda uning paobahan sane wenten ring soangsoang sisia punika. Nurkancana lan Sunartana (1986:1) maosang evaluasi pendidikan punika sakadi parisolah utawi pidabdab anggen nentuang biji ri sajeroning paajah-ajah utawi sane wenten paiketannyane sareng paajahajah. Evaluasi prasida ngicen orti indik kakirangan jadma punika lan mangda 
uning indik undagan pikolih pakaryan sane kamargiang. Evaluasi puniki mawiguna pisan anggen nguningin pikolih ri kala nglaksanayang parikrama-parikrama paajah-ajah ring undagan Taman Kanak-kanak (TK), Sekolah Dasar (SD), Sekolah Menengah Pertama (SMP), Sekolah Menengah Atas (SMA), lan Perguruan Tinggi.

Tetujon evaluasi, Sukardi (2010:9) maosang wenten nenem tetujon evaluasi pikenoh malajah inggih punika: (1) menilai napike tetujon punika prasida kapolihang, (2) ngukur soroh-soroh aspek plajahan sane bervariasi, (3) sakadi piranti anggen nguningin napi sane sisia sampun kauningin, (4) anggen ngicenin rasa ngaat sisia ri kala malajah, (5) nyiagayang orti anggen tetujon bimbingan lan konseling, (6) ngaryanin pikolih evaluasi anggen dasar paubahan kurikulum. Anas Sudijono (2006:16) taler maosang tetujon evaluasi ring paajah-ajah wenten kalih sorohnyane minakadi, tetujon lumrah (umum) lan tetujon khusus.

Teknik evaluasi, teknik evaluasi inggih punika tata cara nglaksanayang evaluasi mangda ngamolihang tetujon sane patut. Daryanto (2005:28) maosang teknik evaluasi kakepah dados kalih soroh sakadi teknik non tes lan teknik tes. Anas Sudijono (2006:68) maosang wenten soroh tes sane manut kawigunannyane anggen piranti ngukur paobahan malajah para sisia. Yening cingak saking kawigunan tes sane kadadosang piranti ngukur paobahan malajah para sisia, tes prasida kabinayang dados nenem soroh, inggih punika: 1) tes seleksi, 2) tes awal (pangawit), 3) tes akhir (panguntat), 4) tes diagnostik, 5) tes formatif lan 6) tes sumatif.

Soroh tes saking aspek psikis sane meled kaungkap. Kacingak saking aspek kejiwaan sane meled kaungkap, tes prasida kabinayang dados lima soroh, inggih punika: a) tes intelegensi, b) tes kemampuan, c) tes sikap (parisolah), d) tes kepribadian, e) tes pikolih malajah. Soroh sane lianan, kacingak saking akehnyane jadma sane nyarengin tes, tes prasida kabinayang dados kalih soroh, inggih punika: 1) tes individual (preragan), 2) tes kelompok (seka). Kacingak saking galah sane sampun kasayagayang majeng ring testee anggen muputang tes, tes prasida kabinayang dados kalih soroh, inggih punika: 1) power test, 2) speed test.

Kacingak saking wentuk responnyane, tes prasida kabinayang dados kalih soroh, inggih punika: 1) verbal test, 2) nonverbal test. Kacingak saking cara ngajuang pitaken sareng cara ngicenin pasaur, tes prasida kabinayang dados kalih soroh, inggih punika: 1) tes tertulis (kasurat), 2) tes lisan. Arikunto (2005:49-50) taler maosang wenten soroh tes pikenoh malajah sane palihannyane inggih punika 1) Manut tata cara makarya, prasida kakepah dados tigang soroh inggih punika: a) tes sane kakaryanin olih guru, b) tes sane kakaryanin saking jadma sane lianan sane nenten distandarisasikan, c) tes standar. 2) Manut kriteria wangun pasaur, prasida kakepah dados tigang soroh inggih punika: a) tes esai (uraian), b) tes jawaban pendek (pasaur bawak), c) tes pilihan. Wangun saking tes pilihan wenten tatiga inggih punika : 1) tes benar salah (patut lan iwang), 2) tes penjodohan, 3) tes pilihan ganda.

Wangun tes, Ngraosang indik wangun tes, ring kawiaktiannyane tes punika ngranjing ring soroh teknik tes ring ajeng. Samian wangun tes punika nglimbak pisan, ngraosang indik tes puniki nenten kapalasang sareng teknik tes. Wangun tes punika kabinayang dados tigang wangun inggih punika tes 
uraian, tes objektif, lan tes uraian obyektif.

Wangun tes uraian utawi esai inggih punika wangun pitaken sane nikain sisia nyawis ngangge basa soang-soang. Wangun tes uraian inggih punika mangda sisia punika prasida mikayunin lan kaanggen nguningin sane patut utawi iwang indik pitaken sane sapatutnyane kacawis. Taler, tes sakadi puniki madue karakteristik sane marupa pitaken utawi perintah majeng ring para testee mangda ngicenin teges, panampen, penafsiran, membandingkan, minayang miwah sane lianan. Ring tes uraian puniki pitakennyane kakawitin nganggen kruna-kruna sakadi: tlatarang, terangkan, uraikan, kenapi, sapunapi, utawi kruna-kruna sane marupa sakadi ring ajeng (Anas Sudijono 2006:100).

Wangun tes objektif inggih punika pateh sakadi tes pasaur bawak. Manut sareng murdanyane, tes pasaur bawak nganikain para sisia nyawis pitaken nganggen pasaur sane bawak. Nyawisnyane punika nyelehin kodekode sane sampun kacumawisang, sakadi ngicen tanda silang, ngelingkerin, utawi nyelemang pasaur sane patut. Soroh wangun tes objektif wenten petang soroh sakadi tes benar salah (patut lan iwang), tes pilihan ganda, tes isian lan tes penjodohan. Indik tegesnyane sampun katlatarang ring ajeng.

wangun tes uraian objektif inggih punika paiketan tes uraian sareng tes obyektif. Kacingak ring pasaur pitaken sane nikain sisia nyawis pitaken sane ngangge basa soang-soang puniki kahanan tes uraian. Wangun tes uraian obyektif puniki nenten sanget katlatarang santukan ring tetilikan puniki ngangge tes pilihan ganda.Tes sane kaanggen ring tetilikan puniki inggih punika tes pilihan ganda, mangkin jagi katlatarang tegesnyane ngenenin indik tes pilihan ganda.

Sukardi (2010:125) maosang tes pilihan ganda inggih punika soroh tes obyektif sane pinih akeh kaanggen olih para guru. Tes puniki prasida ngukur aji pangweruh sane jimbar ring undagan sane mabinayan. Suharsimi Arikunto (2005:164) maosang tes pilihan ganda inggih punika tes sane ri kala panureksaannyane prasida kalaksanayang secara objektif. Tes pilihan ganda inggih punika tes sane ngicenin majeng ring para sisia antuk sejumlah alternatif pasaur, lumrahnyane mawit saking tatiga kantos lalima alternatif ri sajeroning soang-soang pitaken lan tugas sisia inggih punika milihin sinalih tunggil ri sajeroning alternatif punika sane madasar antuk parindikan sane mapikenoh punika (Slameto 2001:59). Ring makudang-kudang panampen para sujana punika prasida kacutetang tes pilihan ganda inggih punika tes sane madue awig-awig sakadi tes sane becik, inggian punika kacingak saking objektivitas, reliabilitas, lan daya pembeda antara sisia sane waged sareng sisia sane belog. Kacingak ring wangunnyane, pitaken pilihan ganda kakepah dados kalih soroh inggih punika: 1) unteng pitaken sane ngicen pikobet jagi katakenang, 2) samian pilihan utawi kemungkinan pasaur.

Nureksain tes pilihan ganda sareng taksonomi bloom, taksonomi puniki cutetnyane inggih punika taksonomi tetujon paajah-ajah sane nganggen pendekatan psikologis, inggian punika ri sajeroning dimensi psikologis napi sane maubah majeng ring para sisia. Basrowi lan Siskandar (2012:104) maosang Benyamin S. Bloom ngepah tetujon paajah-ajah dados tiga wagian inggih punika: (1) aji pangweruh (ranah kognitif), 
parilaksana (ranah afektif), (3) kebisan (ranah psikomotor).

Ring ranah kognitif puniki kawagedan nerapang uger-uger anggen muputang pikobet sane wenten ring lapangan. Taler ranah kognitif puniki naenin kasengguh malajah kontekstual. Ring ranah kognitif puniki wenten nenem pahannyane, inggih punika : C1 ingatan, C2 pangresep (pemahaman), C3 penerapan, C4 nureksain (nureksain), C5 sintesis, C6 evaluasi.

Ranah afektif puniki ranah sane mapaiketan sareng laksana, biji, pangrasa, emosi lan derajat penerimaan utawi penolakan ri sajeroning penandang ring parikrama malajah. Ring ranah afektif puniki wenten lima pahannyane, inggih punika : penerimaan, nampenin (menanggapi), penilaian, parikrama (organisasi), karakteristik.

Ring ranah psikomotor puniki nglibatang gerakan lan koordinasi jasmani, kebisan (keterampilan) motorik lan kemampuan fisik. Ring ranah psikomotor puniki wenten pitu pahannyane, inggih punika : persepsi, kesiapan, reaksi sane kaarahang, reaksi natural, reaksi sane kompleks, adaptasi, kreativitas.

Paiketan peplajahan sareng tes pilihan ganda, peplajahan inggih punika makasami wentuk ajah-ajahan sane kaanggen ri sajeroning ngwantu guru (instuktor) ri tatkala ngamargiang parikrama paajah-ajah. Peplajahan puniki sane kaanggen unteng olih guru ri kala ngaryanin tes pilihan ganda. Peplajahan mangda madue paiketan sane pinih utama ri tatkala ngaryanin ajah-ajahan tes sane jagi kaicen majeng ring para sisia. Yening peplajahan sampun mapaiketan sareng ajah-ajahan tes punika kabaosang sampun madue validitas isi. Sakadi imba, tes sane kakaryanin anggen ngukur kaweruhan sisia indik basita paribasa, yening ring peplajahan sampun mapaiketan sareng tes punika sampun kawastanin valid. Krana yaktinyane samian soang-soang pitaken sane mapaiketan sareng ajahajahan ngenenin indik basita paribasa sane wenten ring $R P P$.

Sinalih tunggil unteng tes inggih punika tes sepatutnyane madue ceciren sane becik. Validitas inggih punika sinalih tunggil ceciren tes sane becik. Wenten makudang-kudang soroh validitas tes inggih punika validitas isi, konstruksi, lan prediksi. Validitas sane mawiguna ring tes inggih punika validitas isi. Anas Sudijono (2006:164) maosang validitas isi inggih punika validitas sane katilik ring daging tes punika sane kadadosang piranti ngukur pikolih malajah, minakadi sapunapi indik tes pikolih malajah sane kadadosang piranti ngukur pikolih malajah para sisia.

\section{KRAMANING TETILIKAN}

Tetilikan puniki ngangge tetilikan deskriptif kualitatif. Wenten nenem papalih paridabdab kramaning tetilikan sane kaanggen ring tetilikan puniki, sakadi: (1) palihan tetilikan; palihan tetilikan inggih punika parindikan sane jangkep, pangrencana sane sampun masusun becik lan spesifik ngenenin indik tata cara ngamolihang, nyelehin, lan menginterpretasi data. Tetilikan puniki kamargiang mangda uning napike anut ajah-ajahan tes ring peplajahan lan dadalan sane ngawinang anut utawi nenten anut ring peplajahan. Tetilikan puniki madue teges parindikan sane katilik jati-jati wenten lan nenten wenten kakawian (rekayasa).

(2) Jejering lan penandang tetilikan, sane pinaka jejering tetilikan sane kalaksanayang inggih punika tes ulangan umum semester ganjil warsa 2016/2017 peplajahan basa Bali kelas 
VII ring SMP Negeri 5 Singaraja, penandang tetilikan parindikan sane pacang katureksain ri sajeroning tetilikan, pamekasnyane penandang tetilikan puniki, (a) kaanutan pitakenpitaken tes ring RPP plajahan, (b) pitaken tes sane anut ring taksonomi bloom.

(3) Mupulang data, kramaning mupulang data sane kaanggen ring tetilikan puniki inggih punika kramaning dokumentasi. Kramaning dokumentasi inggih punika ngrereh data ngenenin indik parindikan-parindikan utawi variabel sane marupa catatan, transkrip, buku, surat kabar, majalah, prasasti, lan agenda (Trianto 2011:278).

(4) Piranti tetilikan, piranti tetilikan inggih punika piranti sane kaanggen ngamolihang data sane mapikenoh anggen nyawis pikobet tetilikan. Piranti sane kaanggen ring tetilikan puniki inggih punika piranti kramaning dokumentasi sane kaanggen marupa tes, RPP, LKS.

(5) Piranti tetilikan sane kaanggen nepasin pikobet sane kaping kalih inggih punika peplajahan sane mapaiketan ring taksonomi bloom patut nganggen lepihan data. (6) Data tureksa, inggih punika utsaha utawi cara anggen ngolah data mangda dados informasi mangda karakteristik data punika prasida karesepang lan mapikolih anggen nyawis pikobet, sane utama inggih punika pikobet sane mapaiketan sareng tetilikan. Pamargi data tureksa sane kalaksanayang ri sajeroning tetilikan puniki inggih punika : 1) nyelehin data (reduksi data), 2) nyajiang data (penyajian data), 3) pamicutet (penyimpulan).

\section{PIKOLIH LAN TETEPASAN}

Pikolih lan tetepasan tetilikan nureksain kaanutan pitaken-pitaken tes ulangan umum semester ganjil warsa
2016/2017 ring RPP peplajahan basa Bali kelas VII ring SMP Negeri 5 Singaraja pacang katlatarang sejangkepnyane. Pikolih saking nureksain kaanutan pitaken tes ulangan umum ring RPP peplajahan sane kaicen olih guru lan makudangkudang pitaken tes ulangan umum sane ngranjing ring taksonomi bloom pacang katlatarang ring sor puniki.

Indik kaanutan peplajahan tes ring RPP peplajahan sane kaicen olih guru wenten telung dasa nem (36) pitaken tes inggih punika peplajahan tes sane nomor $1,2,3,5,6,7,8,9,10$, $11,12,14,15,16,17,18,19,21,22$, $23,24,26,28,29,30,31,32,33,35$, $36,39,46,47,48,49,50$ sane pinaka peplajahan tes sane anut ring $R P P$ peplajahan sane kaicen olih guru basa Bali ring SMP Negeri 5 Singaraja lan sane patbelas pitaken tes inggih punika peplajahan tes sane nomor 4, 13, 20, $25,27,34,37,38,40,41,42,43,44$, 45 sane pinaka peplajahan tes sane nenten anut ring RPP peplajahan sane kaicen olih guru basa Bali ring SMP Negeri 5 Singaraja.

Nglantur indik makudangkudang pitaken tes ulangan umum anut ring taksonomi bloom. Wenten petang dasa pat (44) pitaken tes sane ngranjing ring ranah kognitif, inggian punika pitaken nomor 1, 2, 3, 4, 5, 6, 7, $8,9,10,11,12,13,14,15,16,17,18$, $20,21,22,23,24,25,26,27,28,29$, $30,31,32,33,34,37,38,39,40,41$, $42,43,44,45,49,50$. Pitaken tes sane ngranjing ring ranah afektif wenten kalih (2) inggih punika pitaken nomor 35, 36. Taler pitaken sane ngranjing ring ranah psikomotor wenten patpat (4) inggih punika pitaken nomor 19, 46, 47, 48.

Tetepasan saking kalih (2) nureksain inggian punika kaanutan pitaken tes ring RPP peplajahan sane kaicen olih guru lan makudang-kudang pitaken tes sane ngranjing ring 
taksonomi bloom pacang katlatarang sejangkepnyane ring sor.

Mawit saking tetepasan

pikobet kapertama inggih punika kaanutan pitaken tes ring RPP peplajahan sane kaicen olih guru. Wenten telung dasa nem (36) pitaken sane peplajahan tes anut ring peplajahan sane kaicen olih guru ring $R P P$. Pitaken-pitaken sane ngranjing inggih punika pitaken nomor 1, 2, 3, 5, $6,7,8,9,10,11,12,14,15,16,17,18$, $19,21,22,23,24,26,28,29,30,31$, 32, 33, 35, 36, 39, 46, 47, 48, 49, 50. Makasamian pitaken puniki pacang katlatarang sejangkepnyane.

Mawit saking pitaken nomor 1 , $2,3,5,6,7,8,9,10$, peplajahan saking pitaken puniki inggih punika wacana aksara Bali sane sampun wenten ring RPP lan buku LKS Widyasastra kelas 7, taler kompetensi dasar saking peplajahan pitaken puniki inggih punika ngwacen wacana aksara Bali sane sampun anut ring $R P P$.

Nglantur ring pitaken nomor 24, 26, 28, 29, 30, 31. Peplajahan saking pitaken puniki inggih punika kruna basa Bali sane sampun wenten ring RPP lan buku LKS Widyasastra kelas 7, taler kompetensi dasar saking peplajahan pitaken puniki inggih punika nyutetang mawali daging bebaosan sane kabaktayang ri sajeroning makudang-kudang lengkara sane sampun anut ring $R P P$.

Nglantur ring pitaken nomor 11, 14, 15, 19, 46, 47, 48. Peplajahan saking pitaken puniki inggih punika nyurat aksara Bali sane sampun wenten ring RPP lan buku LKS Widyasastra kelas 7 , taler kompetensi dasar saking peplajahan pitaken puniki inggih punika nyuratang sahananing kruna utawi lengkara nganggen aksara Bali sane sampun anut ring $R P P$.

Nglantur ring pitaken tes nomor 12, 16, 17. Peplajahan saking pitaken tes puniki inggih punika pasang aksara Bali sane sampun wenten ring RPP lan buku LKS Widyasastra kelas 7 , taler kompetensi dasar saking peplajahan pitaken puniki inggih punika nyuratang sahananing kruna utawi lengkara nganggen aksara Bali sane sampun anut ring $R P P$

Nglantur ring pitaken tes nomor 18, 21. Peplajahan saking pitaken puniki inggih punika nyurat aksara latin sane sampun wenten ring RPP lan buku LKS Widyasastra kelas 7, taler kompetensi dasar saking peplajahan pitaken puniki inggih punika nyuratang sahananing kruna utawi lengkara nganggen aksara Bali sane sampun anut ring RPP. Nglantur ring pitaken tes nomor 22, 23, 32, 33, 35. Peplajahan saking pitaken puniki inggih punika mabebaosan sane sampun wenten ring RPP lan buku $L K S$ Widyasastra kelas 7 , taler kompetensi dasar saking peplajahan pitaken puniki inggih punika nyutetang mawali daging bebaosan sane kabaktayang ri sajeroning makudang-kudang lengkara sane sampun anut ring $R P P$. Nglantur ring pitaken tes nomor 36, peplajahan saking pitaken puniki inggih punika parilaksana sane sampun wenten ring RPP lan buku LKS Widyasastra kelas 7, taler kompetensi dasar saking peplajahan pitaken puniki inggih punika nyutetang daging orti sane kawacen ri sajeroning makudang-kudang lengkara sane sampun anut ring $R P P$.

Nglantur ring pitaken tes nomor 39, 50. Peplajahan saking pitaken ring ajeng inggih punika indik orti sane sampun wenten ring RPP lan buku LKS Widyasastra kelas 7, taler kompetensi dasar saking peplajahan pitaken puniki inggih punika nyutetang daging orti sane kawacen ri sajeroning makudang-kudang lengkara sane sampun anut ring $R P P$. 
Nglantur ring pitaken tes nomor 49 , peplajahan saking pitaken puniki inggih punika wacana aksara Bali sane sampun wenten ring RPP lan buku LKS Widyasastra kelas 7, taler kompetensi dasar saking peplajahan pitaken puniki inggih punika ngwacen wacana aksara Bali sane sampun anut ring $R P P$.

Wenten patbelas (14) pitaken sane peplajahan tes nenten anut ring $R P P$ peplajahan sane kaicen olih guru. Pitaken-pitaken sane ngranjing inggih punika pitaken nomor $4,13,20,25,27$, 34, 37, 38, 40, 41, 42, 43, 44, 45. Makasamian pitaken puniki pacang katlatarang sejangkepnyane.

Mawit saking pitaken tes nomor 4, 25, 27. Gebogan pitaken puniki ngranjing ring peplajahan kruna basa Bali sane peplajahannyane nenten wenten ring RPP lan buku LKS Widyasastra kelas 7, taler kompetensi dasar saking peplajahan pitaken puniki nenten wenten kaunggahang ring $R P P$.

Nglantur ring pitaken tes nomor 13, pitaken puniki ngranjing ring peplajahan nyurat aksara Bali sane peplajahannyane nenten wenten ring RPP lan buku LKS Widyasastra kelas 7, taler kompetensi dasar saking peplajahan pitaken puniki nenten wenten kaunggahang ring RPP.

Nglantur ring pitaken tes nomor 20, 34. Pitaken puniki ngranjing ring peplajahan mabebaosan sane peplajahannyane nenten wenten ring RPP lan buku LKS Widyasastra kelas 7, taler kompetensi dasar saking peplajahan pitaken puniki nenten wenten kaunggahang ring $R P P$.

Nglantur ring pitaken tes nomor 37, 38, 40. Pitaken puniki ngranjing ring peplajahan parilaksana sane peplajahannyane nenten wenten ring RPP lan buku LKS Widyasastra kelas 7, taler kompetensi dasar saking peplajahan pitaken puniki nenten wenten kaunggahang ring $R P P$.
Nglantur ring pitaken tes nomor 41, 42. Pitaken puniki ngranjing ring peplajahan sor singgih basa sane peplajahannyane nenten wenten ring RPP lan buku LKS Widyasastra kelas 7, taler kompetensi dasar saking peplajahan pitaken puniki nenten wenten kaunggahang ring RPP.

Nglantur ring pitaken tes nomor 43, 44. Pitaken puniki ngranjing ring peplajahan indik museum sane peplajahannyane nenten wenten ring RPP lan buku LKS Widyasastra kelas 7, taler kompetensi dasar saking peplajahan pitaken puniki nenten wenten kaunggahang ring $R P P$.

Nglantur ring pitaken tes nomor 45, pitaken puniki ngranjing ring peplajahan indik pakaseh sane peplajahannyane nenten wenten ring RPP lan buku LKS Widyasastra kelas 7, taler kompetensi dasar saking peplajahan pitaken puniki nenten wenten kaunggahang ring RPP.

Nglantur ring tetepasan pikobet sane kaping kalih inggih punika makudang-kudang pitaken tes ulangan umum sane ngranjing ring taksonomi bloom. Wenten telung dasa dua (32) pitaken tes sane ngranjing ring ranah kognitif, tes ulangan umum sane ngranjing ranah $\mathrm{C} 1$ ingatan wenten duangdasa (20) pitaken, tes ulangan umum sane ngranjing ranah $\mathrm{C} 2$ pangresep wenten siki (1) pitaken, tes sane ngranjing ranah C4 nureksain (analisis) inggih punika wenten kutus (8) pitaken, tes sane ngranjing ranah C1 ingatan lan C4 nureksain (analisis) inggih punika wenten kalih (2).

Pitaken tes sane ngranjing ring ranah afektif pamekasnyane ring A5 karakterisasi wenten nenem (6) pitaken. Salanturnyane wenten tes sane ngranjing kalih ranah inggih punika ranah kognitif (C1 ingatan) lan ranah afektif (A4 parikrama (organisasi)) inggih punika wenten siki (1) pitaken. 
Ring ranah psikomotor puniki, pitaken ring tes ulangan umum punika wenten taler ngranjing ring ranah kognitif lan afektif. Tes sane ngranjing ranah kognitif lan ranah psikomotor inggian punika C4 nureksain (analisis) lan P3 reaksi sane kaarahang. Tes sane ngranjing ranah kognitif, afektif lan psikomotor inggian punika C3 penerapan, A5 karakterisasi lan P3 reaksi sane kaarahang.

\section{PAMUPUT}

Mawit saking pikolih sane sampun katlatarang ring ajeng indik pikolih lan tetepasan ngenenin indik kaanutan pitaken-pitaken tes ulangan umum semester ganjil warsa 2016/2017 ring RPP peplajahan basa Bali kelas VII ring SMP Negeri 5 Singaraja lan makudang-kudang pitaken tes ulangan umum semester ganjil warsa 2016/2017 peplajahan basa Bali kelas VII ring SMP Negeri 5 Singaraja anut ring Taksonomi bloom. Ngenenin indik punika prasida kaambil tetingkesan sakadi ring sor.

(1) Sakadi sane sampun katlatarang ring ajeng indik kaanutan pitaken-pitaken tes ulangan umum semester ganjil warsa 2016/2017 ring RPP peplajahan basa Bali kelas VII ring SMP Negeri 5 Singaraja nenten samian peplajahan tes punika anut ring $R P P$ peplajahan sane kaicen olih guru ring SMP Negeri 5 Singaraja. Parindikan puniki prasida kacingak wenten telung dasa nem (72\%) saking seket (50) pitaken tes sane peplajahan tes anut ring RPP peplajahan sane kaicen olih guru. Taler wenten patbelas (28\%) saking seket (50) pitaken tes sane peplajahan tes nenten anut ring $R P P$ peplajahan sane kaicen olih guru ring SMP Negeri 5 Singaraja.

(2) Makudang-kudang pitaken tes ulangan umum semester ganjil warsa 2016/2017 peplajahan basa Bali kelas
VII ring SMP Negeri 5 Singaraja anut ring taksonomi bloom. Pitaken sane ngranjing ring ranah kognitif wantah kawangun antuk C1 ingatan, C2 pangresep (pemahaman), C4 nureksain (analisis). Ring ranah afektif ring tes ulangan umum peplajahan basa Bali kawangun antuk A4 parikrama (organisasi), A5 karakteristik. Ring ranah psikomotor ring tes ulangan umum peplajahan basa Bali wantah kawangun antuk P3 reaksi sane kaarahang.

Manut ring pikolih tetilikan ring ajeng, wenten makudang-kudang piteket jagi kawedarang inggih punika (1) Majeng ring guru basa Bali, guru basa Bali pamucuknyane, sane nyurat pitaken tes mangda nincapang malih kaweruhan indik evaluasi lan mangda nyelehin malih pitaken tes sane kakaryanin napike sampun anut peplajahan tes ring peplajahan sane kaicen olih guru. (2) Majeng ring sisia, sisia mangda pinih sering mlajahang dewek lan pinih akeh ngwacen buku. Taler sisia mangda sering mlajahin peplajahan sane kaicen olih guru ring sekolah mangda ri kala sisia ngamolihang tes ulangan umum, sisia prasida becik nyaurin pitaken tes punika.

(3) Majeng ring panilik, panilik mangda malih nincapang kaweruhan indik karya ilmiah, yening benjangan pungkur malih ngaryanin karya ilmiah mangda prasida ngaryanin sane pinih becik lan prasida makarya tes sane anut ring peplajahan sane kaicen olih guru. (4) Majeng ring panilik sane lianan, panilik sane lianan sane jagi nyelehin indik tes mangda nglaksanayang tetilikan sane mesaih mangda ngamolihang parindikan sane lianan sane mapaiketan sareng tes pilihan ganda, kantos tetilikan sane ngenenin indik tes pilihan ganda basa Bali sayan jangkep. (5) Majeng ring wewidangan paajah-ajah, tetilikan 
puniki kaaptiang mangda prasida dados tatuladan ri sajeroning makarya tes ulangan umum peplajahan basa Bali. Mangda peplajahan saking tes ulangan umum punika anut ring peplajahan sane kaicen olih guru. Turmaning ri kala makarya tes ulangan umum mangda madasar antuk kaanutan peplajahan sane wenten ring buku lan RPP pembelajaran.

\section{KAPUSTAKAAN}

Anas, Sudijono. 2006. Pengantar Evaluasi Pendidikan. Jakarta: PT. Raja Grafindo Persada.

Arikunto, Suharsimi. 2005. DasarDasar Evaluasi Pendidikan. Edisi Revisi. Jakarta: Bumi Aksara.
Basrowi \& Siskandar. 2012. Evaluasi Belajar Berbasis Kinerja. Bandung : Karya Putra Darwati Bandung.

Daryanto. 2005. Evaluasi Pendidikan. Jakarta: PT Rineka Cipta.

Nurkancana, Wayan dan PPN Sunartana. 1986. Evaluasi Pendidikan. Surabaya: Usaha Nasional.

Slameto. 2001. Evaluasi Pendidikan. Jakarta: Bumi Aksara.

Sukardi. 2010. Metodologi Penelitian Pendidikan. Jakarta: PT. Bumi Aksara.

Trianto. 2011. Model Pembelajaran Terpadu. Jakarta: Bumi Aksara. 